\title{
O papel da geografia em face da crise ambiental
}

\author{
RAQUEL DEZIDÉRIO SOUTO ${ }^{I}$
}

\section{Introdução}

A

TEMÁTICA AMBIENTAL se popularizou em diversos campos do conhecimento científico, desde o aprofundamento da crise ambiental, a partir

de meados do século XX. Mas já era objeto das preocupações intelectuais desde o final do século XVIII, quando o foco passou da influência do ambiente sobre o homem para a influência do homem sobre o ambiente (Pádua, 2010).

A crise ambiental também é caracterizada como uma crise do conhecimento (Moreira, 2006; Leff, 2007), à medida que os conceitos e os métodos usualmente aplicados não são mais adequados para interpretar e explicar a realidade. As profundas modificações ocasionadas pelo progresso do capitalismo, quer seja nas culturas, quer seja nas relações de poder entre Estados-nacionais, tem configurado um novo espaço geográfico, ao qual Milton Santos (1996) conceituou como o meio técnico-científico-informacional.

Em maior ou menor grau, a temática ambiental sempre esteve presente na geografia, podendo ser distintos dois momentos: i) um período naturalista, que vai da consolidação da geografia como ciência no século XIX a meados do século XX; e ii) um período ambientalista, que vai das décadas de 1950 e 1960 até os dias atuais (Mendonça, 2012). Durante todo esse tempo, houve um longo percurso de (re)formulação do pensamento geográfico. Um percurso que se inicia com a abordagem puramente descritiva e classificatória do ambiente, sem inclusão do homem na análise; passa pela fase em que o homem é incluído, porém ainda apenas como um componente natural; e culmina na fase em que já se considerava o homem como um ser social em relação com o ambiente. Tais visões não são delimitadas temporalmente independentemente umas das outras. Dito de outro modo, o fim do período de predomínio de determinada visão não coincide temporalmente com o início do período de adoção de outra (Moraes, 2007). As visões concorrem e há aquelas que ainda hoje são adotadas, mesmo com o avanço do pensamento geográfico.

A cada mudança de visão a respeito do objeto da geografia correspondem naturalmente mudanças nos métodos adotados. Cada método apresenta potencialidades e limitações em face da tarefa de lançar luz aos problemas ligados à crise ambiental, já que a utilização de um método denota como se pretende explicar e estabelecer uma forma de intervenção no mundo (Moreira, 2006). Certas pesquisas, que conjugam mais de um tipo de abordagem, têm obtido 
sucesso em equacionar os problemas pertinentes à crise ambiental (Mendonça, 2012), no entanto há dificuldades de aceitação por parte dos geógrafos de uma pluralidade de métodos (Moraes, 2007). O mesmo ocorre em outras ciências, além da resistência em reconhecer a diferença entre o domínio das ciências naturais e humanas (Moraes, 2007; Moreira, 2006; Leff, 2007). A tendência geral é de eleição de um método universal, da crença na unicidade da ciência e da afirmação da supremacia de um método sobre outro.

O presente texto se propõe a tecer algumas considerações sobre as vantagens e limitações da geografia para análise e apontamento de soluções para a atual crise ambiental. Para tanto, parte-se de alguns pressupostos: de que a natureza da problemática ambiental é multifacetária (Leff, 2007), que o meio é o mesmo que o meio ambiente (Santos, 2006) e que a geografia é uma ciência política (Moraes, 2007).

\section{A geografia naturalista e o homem natural}

O período que vai da consolidação da geografia como ciência, no século XIX, até meados do século XX foi caracterizado por Mendonça (2012) como do naturalismo na geografia, à medida que as abordagens utilizadas à época enfocavam a natureza desprovida do elemento humano ou considerando o homem como mais um elemento natural. $\mathrm{O}$ foco estava na relação das comunidades humanas com o meio e não na relação entre os homens, agregados em sociedade. A única exceção é o pensamento de Élisée Reclus, datado desse período, porém só reconhecido na década de 1960 (Mendonça, 2012). Reclus já apresentava uma visão ambientalista integradora, profundamente contestadora do sistema capitalista e atribuindo-lhe responsabilidade sobre a degradação ambiental (Farenzena et al., 2001).

O naturalismo geográfico desse período resultou da preocupação em conhecer a superfície da Terra e controlar a natureza (Farenzena et al., 2001) e foi impregnado pelos postulados positivistas e empiristas da época (Mendonça, 2012). Dentre as características desse tipo de pensamento geográfico podem ser citados: o privilégio do empirismo e da indução, a resistência na aceitação da diversidade de métodos de interpretação; e a visão de unicidade da geografia (Moraes, 2007).

Muito se critica a respeito dessa fase de naturalismo geográfico, à medida que a geografia é despossuída de qualquer conteúdo político (Moraes, 2007; Moreira, 2006; Mendonça, 2012; Porto-Gonçalves, 1988), quando muito, os homens eram abordados em estudos sobre população, nunca enquanto sociedade (Moraes, 2007). No entanto, uma série de princípios norteava as pesquisas geográficas nesse tempo, alguns dos quais poderiam ser úteis na abordagem da atual crise ambiental. Esse ponto será retomado adiante.

[...] o princípio da unidade terrestre - Terra é um todo que só pode ser compreendido numa visão de conjunto; princípio da individualidade - cada lugar tem uma feição que the é própria e que não se reproduz de modo igual em outro 
lugar; princípio da atividade - tudo na natureza está em constante dinamismo; princípio da conexão - todos os elementos da superfície terrestre e todos os lugares se inter-relacionam; princípio da comparação - a diversidade dos lugares só pode ser apreendida pela contraposição das individualidades; princípio da exaustão - todo fenômeno manifesta-se numa posição variável do planeta; princípio da localização - a manifestação de todo fenômeno é passível de ser delimitada. (Moraes, 2007, p.42-3, grifos do autor)

Alexander von Humboldt e Carl Ritter formaram o início do período científico na geografia (Moreira, 2006; Gomes, 2011). Humboldt era naturalista e seus principais livros, Quadros da natureza e Cosmos, apresentavam descrições físicas da superfície terrestre, já que considerava a geografia como "a parte terrestre da ciência do cosmos" (Moraes, 2007, p.62). Humboldt fez diversas expedições de cunho naturalista e enfocava as descrições e catalogações (Mendonça, 2012). Ritter possuía formação em Filosofia e História e dedicou-se a desenvolver uma metodologia para o estudo dos lugares, conferindo-lhes individualidade e colocando o homem como principal elemento (Moraes, 2007). No entanto, o homem era visto como mais um elemento natural, Ritter relacionava as culturas a seus meios (Gomes, 2011), descrevia as várias organizações espaciais dos homens sobre os diferentes lugares (Mendonça, 2012). A coletividade humana era vista como comunidade e não se fazia referência ao relacionamento entre os humanos, apenas destes com o meio.

Friedrich Ratzel também inclui o homem em sua abordagem e segue a tradição de Ritter de restringir a análise ao relacionamento do homem com o meio. Em sua Antropogeografia, adota uma abordagem determinista que considera que o desenvolvimento das comunidades humanas é possível a depender do meio (Mendonça, 2012): "Descrever os movimentos da humanidade sobre a Terra e formular-lhe as leis, tal é o objetivo da antropogeografia” (Ratzel, 1987 apud Gomes, 2011, p.185). Essa ideia também está presente em seu conceito de "espaço vital", o qual relaciona a população de um Estado e a capacidade de utilização e ampliação de seu território (Farenzena et al., 2001). Uma das diferenças entre as abordagens de Ratzel e de Ritter consiste em que o primeiro buscava uma lei geral para correlacionar solo e cultura e, com isso, esperava alçar a Geografia ao status de ciência positiva (Gomes, 2011).

Vale lembrar que as teorias de Ratzel foram utilizadas para legitimar os desígnios expansionistas do Estado alemão recém-formado e que a resistência às suas ideias, no seio da Revolução Francesa, adveio principalmente das ideias de Vidal de La Blache (Moraes, 2007). Porém, não é objetivo do presente texto aprofundar-se sobre a utilização dos discursos científicos para a legitimação política à época.

A abordagem de La Blache da mesma maneira considerava o meio físico apenas como um suporte para o desenvolvimento dos grupos humanos (Mendonça, 2012), mas sua abordagem era possibilista, enquanto a abordagem ratzeliana era determinista (Febvre, 1954 apud Moreira, 2006). Por meio do con- 
ceito de "gêneros de vida", La Blache sugeria que as formas de adaptação dos grupos humanos aos desafios impostos pelo meio eram expressas pelo conjunto articulado de atividades que faziam parte de seu costume (Farenzena et al., 2001). Em Ratzel, o meio determina as comunidades; em La Blache, as comunidades, por meio da cultura, teriam maior ou menor capacidade em lidar com os desafios impostos pelo meio.

As principais críticas de La Blache ao pensamento de Ratzel foram: i) minimização do homem - La Blache maximiza o homem, atribuindo maior foco na História, porém não rompe com a visão de homem natural; ii) sujeição do homem ao meio - para Vidal, o homem era visto como ser criativo, modificador do meio; e iii) visão fatalista e mecanicista da relação homem-meio - La Blache põe fim ao determinismo e a qualquer tentativa de generalização (Moraes, 2007).

Mais do que um agente transformador do meio, La Blache considerava que o homem tanto modificava o meio quanto era modificado por ele. Uma ideia que atravessou o tempo e que pode ser encontrada em diversas obras geográficas até o presente: "O homem faz parte desta cadeia [que une as coisas e os seres] e, em suas relações com o que o cerca, ele é ao mesmo tempo ativo e passivo, sem que seja fácil determinar na maioria dos casos até que ponto ele é um ou outro" (La Blache, 1921 apud Gomes, 2011, p.200).

Quatro geógrafos marcaram a transição do pensamento naturalista para o ambientalista em geografia - Élisée Reclus, Maximilien Sorre, Alfred Hettner e Richard Hartshorne. Desses, Reclus foi o que apresentou as ideias mais avançadas para a época, mas sua obra somente foi reconhecida na década de 1960 (Mendonça, 2012). Da mesma maneira, a obra de Max Sorre somente foi reconhecida mais tarde (Farenzena et al., 2001). Para fins de manutenção da coerência do presente texto, tanto Reclus quanto Max Sorre serão abordados na seção seguinte.

Hettner encaminhou o pensamento geográfico em direção à ecologia ( $\mathrm{Fa}$ renzena et al., 2001), já que priorizava a relação espacial entre a natureza e o homem e utilizava, além das descrições, explicações deduzidas analítica ou sinteticamente (Wolkenburg, 1960 apud Moreira, 2006). Assim como Ritter, buscou conhecer os lugares, porém avançou na corologia. Enquanto para Ritter a região era um recurso de método, era algo estanque, Hettner adotava a concepção lablachiana de região - essa representava o entrecruzamento de fenômenos físicos e humanos, sendo o processo de recortar, em si mesmo, um processo de diferenciação (Moreira, 2006). É interessante ainda notar que Hettner considerava que a geografia poderia se valer de periodizações diferentes da História, uma vez que cada região possui um tempo próprio (Gomes, 2011).

Hartshorne também considerava ser a geografia uma ciência de síntese entre os fenômenos físicos e sociais, mas combateu a pura descrição, tentando oferecer explicações para a configuração das regiões. Assim como Humboldt e Ritter, Hartshorne considerava que os dados a serem escolhidos nos estudos 
geográficos eram aqueles que apresentavam nexo de causalidade entre si. Sua escolha não poderia, portanto, ser fruto de uma percepção imediata, a partir dos sentidos. Hartshorne buscava as generalizações, a partir da objetividade do trabalho geográfico (Gomes, 2011).

Pelo exposto, nota-se que, ainda que houvesse alguma pluralidade de pensamentos no período naturalista da geografia, as atenções estavam voltadas para a compreensão da distribuição dos fenômenos na superfície terrestre. Observa-se a ausência de uma percepção da ocorrência dos fenômenos em diferentes escalas, de uma noção de escala geográfica.

Em face dos problemas circunscritos à atual crise ambiental, a utilização das abordagens geográficas desse período não seria capaz de oferecer um adequado tratamento e solução deles, ainda que possam servir como um ponto de partida válido. A problemática ambiental é multifacetária (Leff, 2007), e o melhor seria que seus aspectos fossem abordados de forma interdependente. Santos (2006, p.11) diz o mesmo a respeito da técnica: “devemos explorar o fenômeno (da técnica) em todas as suas dimensões - desde a propriamente técnica e operacional até as referências culturais e políticas que comandam a sua incorporação na história do mundo e dos lugares". Para esse autor, os enfoques reducionistas são de variados tipos, uma visão puramente ideológica, puramente econômica, ou de preocupação puramente tópica, ou, como no caso, puramente naturalista, não é adequada para tratar a problemática ambiental atual, uma vez que a realidade é complexa.

Tais abordagens estão esvaziadas de qualquer conteúdo político e o tratamento da atual crise ambiental necessita apontar no sentido de uma atribuição de responsabilidades, se o que se busca é a sua solução. Conforme Ruy Moreira (2006, p.117) ressalta, a fragilidade do projeto da geografia da civilização aquela que toma a paisagem para analisar a relação homem-meio, consiste na "visão pouco clara do homem que está em relação com a natureza e por meio da qual produz a cultura que dá argamassa às civilizações" (ibidem). Adicionalmente, a natureza da atualidade é vista como signo e, como tal, torna-se estratégica e política (Santos, 2006). Qualquer abordagem esvaziada de conteúdo político torna-se, portanto, ineficaz e acaba por legitimar a perpetuação do status quo, à medida que não atribui adequadamente as responsabilidades e não aponta para soluções.

Por outro lado, alguns dos princípios que nortearam as pesquisas de campo nesse período (Moraes, 2007) podem ser úteis na abordagem da atual crise ambiental. Dentre os demais, destacam-se: i) o princípio da individualidade, segundo o qual cada lugar tem uma feição própria, não reprodutível - útil para desmistificar afirmações como as de que haveria um receituário padrão de medidas voltadas à promover a sustentabilidade, para ser aplicado aos "países em desenvolvimento", prática normalmente adotada pelos organismos multinacionais; ii) o princípio da atividade, que preconiza que tudo na natureza está em 
constante dinamismo - tal princípio seria útil para salientar a necessidade de adoção de abordagens que levem em conta tal dinamismo e que não tratem o meio sob análise como algo estanque, meio aqui reconhecido como a resultante da integração dos fenômenos naturais e sociais; iii) o princípio da exaustão, segundo o qual todos os fenômenos manifestam-se numa posição variável no planeta - princípio que corrobora o princípio da atividade.

A esse período segue-se o período dominado por uma geografia de cunho ambientalista, na qual o foco das preocupações passa do natural para o humano, mas um humano visto como um ser social, em sociedade.

\section{A geografia ambientalista e o homem social}

Diversos foram os fatores que levaram à crise do pensamento geográfico em meados do século XX. De um modo geral, as visões e métodos geográficos não mais serviam para explicar a contento a realidade que se tornava cada vez mais complexa, com o avanço rápido do capitalismo em nível mundial. Dentre esses fatores, podem ser citados: i) os princípios positivistas haviam se tornado simplistas; ii) as dicotomias não eram mais adequadas; iii) a indefinição do objeto de análise; iv) as dificuldades na generalização; e v) o discurso apolítico da geografia que se sustentava na neutralidade científica (Farenzena et al., 2001).

Nesse contexto, emergem correntes geográficas que se preocupam em avançar para além do pensamento que restringiu a geografia à descrição, configurando o início de um período de reação às monografias regionais, que perduraram até o primeiro quartel do século XX (Gomes, 2011).

A Geografia Crítica, a Geografia Ecológica e a Geografia da Percepção buscam estabelecer relações entre o meio e o homem, mas dessa vez um homem social, enxergado em sociedade (Farenzena et al., 2001); e um meio que não é mais caracterizado como um meio físico de suporte à vida, como no período naturalista da geografia; vai além disso, caracteriza-se como um meio geográfico, como a do meio técnico-científico-informacional, conceituado por Santos (1996).

A Geografia Crítica busca relacionar a estrutura e funcionamento das sociedades modernas e seus efeitos. Seu enfoque não é descritivo, como na fase naturalista da geografia, busca relacionar fatores econômicos, políticos e sociais. Muitos trabalhos apontam para o potencial de degradação ambiental das práticas capitalistas e da cultura do consumo. Já a Geografia da Percepção não apresenta um enfoque tão político e a maioria dos trabalhos transfere a responsabilidade da problemática para o nível individual, fomentando o desenvolvimento de uma "consciência ambiental", por meio de atividades de educação ambiental (Farenzena et al., 2001). De acordo com Mendonça (2012), a Geografia Crítica, de cunho marxista, deu nova visibilidade aos estudos de Geografia Humana e fez que esse ramo fosse reconhecido à época como a vanguarda da geografia. No entanto, ainda de acordo com o mesmo autor, os estudos quase não inseriam as questões ambientais no seu temário, quando o faziam, era de uma forma pobre. 
Assim, nota-se que ao contrário do que se viu na fase naturalista da geografia, quando houve inexpressiva inserção das questões sociais, na fase seguinte, ao menos no período inicial de desenvolvimento da corrente da Geografia Crítica, pouca atenção foi dada aos problemas ambientais. No Brasil, a temática ambiental foi adotada pelos geógrafos críticos por volta dos anos 1980, haja vista a normatização à época das atividades que afetam o ambiente (Farenzena et al., 2001) e a já expressiva urbanização do país:

Em 1980, apenas catorze metrópoles, com mais de 500 mil habitantes, concentravam $61,7 \%$ da população urbana total! Como o Estado investia prioritariamente na criação da infraestrutura de transportes, comunicações e energia, secundarizando investimentos sociais em habitação e saneamento básico, por ex., as cidades vão encenar o triste espetáculo da favelização. Calcula-se hoje, a existência de déficit habitacional da ordem de 10 milhões de residências! (Porto-Gonçalves, 1995, p.323)

A exceção é o pensamento de Reclus, que já adotava uma visão totalizante da sociedade, mas como mencionado antes, seu pensamento só foi reconhecido algumas décadas depois. Ele não reduziu seus estudos à dicotomia entre Geografia Física e Geografia Humana e preocupou-se com os problemas que inter-relacionavam o meio com as atividades humanas (Farenzena et al., 2001), o que mais tarde foi denominado por parte dos geógrafos físicos como "impacto antropogênico" (Mendonça, 2012). Como ilustra Farenzena et al. (2001, p.4):

O trabalho de Reclus representa para sua época uma visão crítica e moderna para os dias de hoje, por se preocupar com problemas que afligiam a sociedade: desenvolvimento industrial e tecnológico, surgimento e expansão de grandes centros urbanos e uso intensivo e depredatório dos recursos naturais que se fortaleciam rapidamente.

Pierre George teceu considerações a respeito da relação homem-meio em inúmeros trabalhos, em princípio, por volta da década de 1930, tratando dos agrupamentos humanos enquanto população e, posteriormente, por volta das décadas de 1950 e 1960, considerando o homem como um ser social e explicando o processo de diferenciação do espaço, segundo o desenvolvimento de determinados tipos de atividades humanas (Ramão, 2012). Avançou o pensamento, por levar em conta a percepção humana e a atribuição de juízos de valor:

O espaço percebido constituirá o meio ambiente? Sem dúvida, e pode-se dizer até que certamente, no plano psicológico. Contudo, o meio ambiente é algo mais ainda: é o resultado de um juízo de valor pronunciado sobre o espaço vivido. Neste juízo de valor o espaço assume uma nova dimensão, e ao solo, ocupado ou não ocupado, passam a integrar-se outros elementos que contribuem para lhes conferir uma certa "qualidade": o ar, a água ... aquilo que os homens transformaram. (George, 1973, p.34)

George também avança no pensamento geográfico quando discute o papel da técnica no espaço humanizado, distinguindo, por exemplo, as organizações do espaço agrícola e do espaço industrial. 
As técnicas criam, ao mesmo tempo, as necessidades de penetração e instalação - como, por exemplo, na exploração das minas - e os meios de realizar a penetração e a instalação. Trata-se, hoje, na descrição do espaço humanizado, muito mais de diferenciação, de nuanças, do que de oposições fundamentais. O homem está em vias de realizar a "arrumação do seu planeta no momento exato em que pretende poder sair dele. Essa arrumação resulta de múltiplos processos de inovações técnicas de todos os gêneros e de certa filosofia da existência. Resulta da escolha e também de pressões, de relações de forças, em que se entremisturam forças naturais e forças "históricas", que procedem das formas de organização escolhidas ou sofridas pelos diversos grupos humanos. (George, 1970, p.5)

George discute ainda que o tempo, antes natural, passa a ser um tempo ritmado pelas atividades relacionadas aos processos produtivos. Ambos esses temas, o papel da técnica e do tempo nas sociedades modernas, foram amplamente desenvolvidos por Santos $(1985 ; 1996)$.

Prisioneiro desse universo ingrato, inquieto ao ver ensombrecer-se o céu e carregar-se de fuligem e de óleo o ar que respira, o citadino quer reconquistar a natureza ou que lhe dá a ilusão de natureza. A ocupação do espaço periurbano ou extraurbano se expressa em termos e "lazeres". A vida do homem moderno, empenhada na economia e na sociedade industriais, seja qual for a sua profissão, é ritmada por ciclos escrupulosamente definidos por convenções de trabalho, e registrada no relógio de ponto ou no registro de antiguidade do trabalhador, ciclo cotidiano, ciclo hebdomadário, ciclo sazonal, ciclo da vida ativa, sendo apenas algumas variantes de acordo com a idade, a profissão, o sexo. Cada ciclo se define por um ritmo de alternação de trabalho e "lazeres". (George, 1970, p.134)

Max Sorre traz para a geografia uma perspectiva ecológica, uma noção de conjunto, semelhante àquela utilizada nas abordagens sistêmicas, as quais serão mencionadas adiante. Em um segundo momento, no entanto, Sorre aproxima-se mais da sociologia, sempre combinando as condições naturais e o homem. Para Sorre, a geografia humana seria ao mesmo tempo uma geografia ecológica, dando ênfase aos processos e concebendo uma noção de meio que comporta três planos - o físico, o biológico e o social (c f. Megale, 1983).

Para Sorre, o espaço geográfico vai se transformando de concreto a abstrato, uma vez que considerar o espaço apenas como a superfície terrestre e atribuir-lhe delimitações físicas não the parecia mais ser suficiente para abarcar outros elementos que deveriam entrar na análise. Para ele, o espaço geográfico seria constituído por "redes auxiliares" - uma de natureza física natural (ou geodésica) e outra, de natureza humana (como linhas de relações terrestres, marítimas e aéreas), todas essas sobrepostas, gerando uma rede resultante, que revelaria o significado espacial das cidades - "em relação ao conjunto é que se determina a situação de um ponto ou de uma área política" (Sorre, 1984, p.144 - grifo do autor).

Sorre (1984) qualifica ainda o espaço em tipos, de acordo com a natureza do estudo a ser realizado, expandindo o leque de possibilidades de abordagens 
geográficas. Para ele, o espaço político é o objeto de análise da geopolítica, sendo privilegiados os estudos sobre as fronteiras e sobre os territórios políticos que, segundo ele, poderiam se ampliar para além de seus limites físicos, a que denominou "espaço nacional móvel" (Sorre, 1984, p.145). Já o espaço vital seria constituído pelos recursos naturais disponíveis ao homem no solo e no subsolo para um grupo de densidade e crescimento limitados. Mas o próprio autor faz a crítica de que tais limites seriam dificilmente definidos: "[...] o conceito de espaço vital também sofre de contingência. Quanto há de arbitrário na avaliação das atuais necessidades? E de relativo na avaliação dos recursos?" (ibidem, p.146). O espaço econômico seria um espaço imaterial, constituído por linhas pelas quais se propagam os movimentos. Daí poderem ser analisados todos os elementos usualmente considerados nas abordagens econômicas - "planos, correntes de circulação, zonas de influência próximas ou distantes, centros de relação, linhas de força" (ibidem, p.148). O espaço social seria "definido como uma teia de relações próximas ou distantes, com alguns pontos privilegiados. [...] Assim se define a área social onde se desenvolve a existência do homem, onde se exerce a atividade de um grupo localizado" (ibidem, p.153).

Ainda nesse período caracterizado por uma geografia de cunho ambientalista, os trabalhos de geografia física começam a incluir a influência das atividades humanas, considerando "questões socioeconômicas e políticas que na ordenação/reordenação do território contribuem para a transformação do ambiente e do homem" (Suertegaray, 1991, p.29). Buscam-se, dessa forma, análises mais abrangentes e configura-se a corrente da Geografia Ecológica. No Brasil, dois nomes importantes dessa corrente são Aziz Ab'Saber e Carlos Augusto de Figueiredo Monteiro (Farenzena et al., 2001).

Mesmo que, no entanto, os estudos incorporassem as atividades humanas, ainda eram compartimentados por áreas de especialização - geomorfologia principalmente, oceanografia, geologia, biogeografia etc., o que dificultava (e ainda dificulta) a aquisição de uma visão mais abrangente sobre a crise ambiental. Essa compartimentalização não foi exclusividade da geografia, mas um movimento que ocorreu em todas as ciências, uma característica da divisão internacional do trabalho e da fragmentação do conhecimento no final do século XX (Suertegaray, 1991, p.29). Nessa mesma via, Ajara (1993, p.11) reforça a necessidade de enfoques mais amplos:

Reconhecendo a imprescindibilidade do enfoque multidisciplinar no trato da questão ambiental, ressalta-se, contudo, a necessidade de superação das abordagens setorializadas que conduzem a uma atomização do conhecimento gerado no âmbito da focalização de problemas ambientais específicos, em detrimento da compreensão da problemática ambiental com base na abordagem dos processos e formas de organização do espaço geográfico, ou seja, das sociedades humanas sobre o território. 
Uma das abordagens em Geografia Física que mais ganharam adeptos quando do tratamento da problemática ambiental foi a abordagem sistêmica, surgida na década de 1950, por influência das ideias neopositivistas. Buscava-se a modelização e quantificação da natureza. Já na década de 1960, foi formulado por Sotchava o conceito de geossistema, que focalizou o quadro natural do planeta, ainda sem incluir as sociedades. Apesar das críticas levantadas, no que concerne à volta ao naturalismo, houve vantagens na adoção desse conceito no âmbito dos estudos de Geografia Física, à medida que é "resultante das tentativas de aplicação da Teoria Geral dos Sistemas à análise do meio natural pela geografia; também pela aproximação da mesma à metodologia ecossistêmica" (Mendonça, 2012, p.31). Conforme explicado por Christofoletti (1995, p.337):

Os sistemas ambientais físicos, também denominados geossistemas, representam a organização espacial resultante da interação dos elementos componentes físicos da natureza (clima, topografia, rochas, águas, vegetação, animais, solos). É o campo de atuação da geografia física. Os sistemas ambientais físicos possuem uma expressão espacial na superfície terrestre, representando uma organização (sistema) composta por elementos, funcionando por meio de fluxos de energia e matéria, dominante em uma interação areal. [...] os ecossistemas são integrados na concepção mais abrangente de geossistema, como elementos componentes na organização espacial. As noções de ecossistema e geossistema não são sinônimas, [...]. Ambas podem ser usadas, pois se completam no aninhamento hierárquico da estruturação sistêmica de análise. (grifo do autor)

Atualmente, as abordagens sistêmicas em Geografia Física já consideram as atividades humanas como um componente do modelo. Muito por influência dos trabalhos de Georges Bertrand, que desenvolveu a noção alemã de paisagem e que inseriu a ação antrópica como elemento da dinâmica das paisagens e do geossistema. Já Jean Tricart introduziu conceitos e metodologias mais abrangentes, como a ecodinâmica e a ecogeografia.

Mesmo assim, os estudos geográficos que se utilizam de enfoques sistêmicos ainda carecem de conteúdo político. A discussão dos resultados obtidos da aplicação dos modelos deve tentar incluir aspectos históricos, políticos e/ou culturais que ajudem a compor um quadro compreensivo, quiçá explicativo. Nesse sentido, muitos autores evocam a transdisciplinaridade como uma maneira de lidar com a complexidade da realidade.

Leff (2007) fez uma discussão abrangente sobre as vantagens e os limites da transdisciplinaridade. $\mathrm{O}$ autor argumentou que mesmo os campos do saber que são inarticuláveis podem ser integrados pelos objetos de pesquisa e que a transdisciplinaridade é responsável pela permuta de conceitos e métodos entre as ciências. Entretanto, há o risco de realização desse processo de maneira inadequada, à medida que não haja bases epistemológicas sólidas nas ciências a serem articuladas. 
Num sentido positivo, o processo transdisciplinar contribui para o avanço do conhecimento enquanto que os conceitos e metodologias importadas de outras ciências, em como certas categorias filosóficas e termos técnicos, são retrabalhados pela ciência importadora até adquirir um sentido próprio no tecido teórico que serve para especificar seu objeto de conhecimento e para explicar os processos materiais de seu campo de experiência. Desta forma, os efeitos positivos dos intercâmbios conceituais entre disciplinas científicas e a internalização do saber ambiental dentro de seus paradigmas teóricos podem contribuir para compreender melhor a articulação dos processos ecossistêmicos, geográficos, econômicos, culturais e sociais que caracterizam uma problemática ambiental complexa. (Leff, 2007, p.85)

O conhecimento das redes também tem sido importante nas pesquisas que visam entender a realidade complexa da atualidade. Nesse sentido, Corrêa (1997, p.285), versando sobre as interações espaciais, é elucidativo: “o ciclo de reprodução do capital [...] constitui-se no processo fundamental que, no capitalismo, origina, direta ou indiretamente, grande parte das interações espaciais”. No entanto, cabe ressaltar que a natureza é incorporada nessas pesquisas com o mesmo valor que aquele presente na visão marxista: uma natureza como valor de uso para as sociedades, ou seja, vista como recurso. Além disso, não se faz referência direta aos recursos, mas sim às atividades econômicas que os consomem, como a agricultura, por exemplo. De todo modo, a metodologia em si poderia ser estendida pela incorporação de aspectos ligados à temática ambiental, como uma rede de distribuição da poluição, considerando-se os diferentes tipos de poluentes e agregando os locais potenciais de ocorrência de injustiças ambientais, no sentido de Alier (2007).

De um modo geral, percebe-se que os estudos geográficos desenvolvidos no atual período da geografia ambientalista tendem a incorporar variáveis tanto físicas quanto sociais no tratamento da problemática ambiental. Muito há por ser desenvolvido, uma vez que ainda que incorporem variáveis sociais, nem sempre os estudos fazem considerações de cunho político. Por outro lado, alguns estudos em Geografia Humana, ainda que relacionados à problemática ambiental, não incorporam variáveis físicas numa perspectiva ecológica. Mesmo que nem sempre seja possível integrar tais aspectos, de naturezas tão distintas, os geógrafos ainda podem recorrer às equipes multidisciplinares ou, conforme sugere Leff (2007), podem buscar o desenvolvimento de conceitos transdisciplinares.

Rouanet, citado por Porto-Gonçalves (1988, p.9), também afirma: “precisamos de um racionalismo novo, fundado numa nova razão". Leff (2007) procura atender essa demanda sugerindo uma racionalidade ambiental, estratégia conceitual que, segundo ele, combate os efeitos ideológicos do reducionismo ecologista e do funcionalismo sistêmico. A racionalidade ambiental seria alcançada a partir das produtividades cultural, tecnológica e ecológica. A produtividade cultural seria mensurada por aspectos econômicos, mas não apenas esses, também aqueles pertinentes aos hábitos das comunidades e como uma maneira 
de resgatar o conhecimento tradicional das formas de produção; a produtividade tecnológica seria avaliada em função da eficiência mecânica e termodinâmica dos processos produtivos; e a produtividade ecológica seria avaliada por um nível determinado de produção de valores de uso "naturais", um conceito que está além do conceito de produtividade primária dos ecossistemas naturais, normalmente avaliada em termos da quantidade de biomassa.

Milton Santos elencou uma série de problemas que resultam das condições da Modernidade, que são resumidos a seguir. Considera que as pesquisas concernentes a esses problemas coletivamente podem ajudar a melhor apresentar a nova configuração do espaço geográfico, do espaço técnico-científico-informacional e, por extensão, podem ajudar no entendimento da problemática ambiental. Definindo melhor esse espaço e as interações que ali ocorrem, favorece-se o entendimento da atual crise ambiental e possibilita-se a proposta de soluções. Como problemas gerais, Santos (1985) elenca: a) configuração da atividade agrícola, levando em conta os componentes técnicos e científicos; b) novas atividades industriais e suas localizações; c) mudanças territoriais das bases produtivas; d) modificações nas redes de transportes e modernização das comunicações; e) financeirização do território; f) tendências a concentração e centralização da atividade econômica; g) complicação dos circuitos de cooperação; e h) novos papéis das cidades de acordo com seus níveis. Como problemas referentes às relações cidade-campo: i) novos insumos do campo; j) deslocamento para o campo de certas atividades industriais; $\mathrm{k}$ ) novas atividades referentes às cidades médias e pequenas; 1) novos fluxos entre a cidade e o campo; e m) novas formas de urbanização do meio rural. Como problemas referentes às relações interurbanas: $\mathrm{n}$ ) novos consumos públicos e privados e a seletividade de sua localização; o) os círculos de cooperação em diversos níveis; e p) o novo papel da entropia das metrópoles. Como problemas referentes à organizaçãa interna das cidades e os novos papéis da metrópole: q) tendência à "dissolução da metrópole”, pelo aumento irrestrito de sua área de influência; e r) consequências da expansão territorial das regiões metropolitanas para a economia e a sociedade urbanas.

\section{Considerações finais}

A partir da observação das abordagens geográficas, tomadas ao longo do tempo, sobre a natureza do homem e sua posição relativamente ao ambiente, podem ser destacados três esquemas, que são semelhantes aos adotados pelas três formas de concepção ecológica (Suertegaray, 1991): i) um esquema em que se considera apenas o ambiente, sem o homem, próprio da Ecologia Natural e semelhante às abordagens adotadas nos estudos geográficos anteriores à fase de consolidação da geografia como uma ciência (ou, no limite, no início desse período); ii) um esquema em que o meio é composto pelo ambiente, incluindo-se o homem, porém o homem é visto ainda como um ser natural, próprio da Ecologia Humana e semelhante às abordagens adotadas no período naturalista da geografia; ou iii) um esquema em que o meio é composto pelo ambien- 
te, incluindo-se o homem, porém o mesmo é visto como um homem social, enquadra-se em uma sociedade, próprio da Ecologia Política e semelhante às abordagens adotadas no período ambientalista da geografia.

A despeito das vantagens e desvantagens da adoção de um ou outro esquema, importa precisar bem o objeto de estudo, tendo-se em mente que cada época e cada objeto demandam uma interdisciplinaridade. O processo histórico muda a significação do objeto, sendo portanto válido rever a sua construção histórica (Santos, 2006). Adotando-se esses cuidados, colabora-se para a correta delimitação do problema e para o alcance de uma metodologia que seja adequada ao seu tratamento.

Santos (1992, p.104) lembra que "os intelectuais eram homens que, na universidade ou fora dela, acreditavam nas ideias que formulavam e formulavam ideias como uma resposta às suas convicções". Essa afirmação evoca o caráter político da ciência. Dito de outro modo, nos lembra que a utilização de uma abordagem geográfica é ao mesmo tempo um ato político (Moraes, 2007). Santos (2000) lembra que as chances de intervenção dos geógrafos no processo de transformação da sociedade estão relacionadas à forma com a qual são conceituadas a disciplina e seu objeto.

Como entraves a serem superados, por vezes, ainda ocorrem os seguintes problemas: a manutenção dos diversos tipos de dicotomias - físico/humano, urbano/rural etc. (Ajara, 1993); a tendência à adoção de uma "neutralidade científica" nos estudos e o empobrecimento do engajamento político do geógrafo (Santos, 2000); a visão do espaço geográfico apenas como uma categoria analítica (Ajara, 1993); a visão de um ambiente externo ao homem (Suertegaray, 1991); a homogeneização de conceitos, devido às dificuldades no trabalho interdisciplinar (Leff, 2007); apego a um formalismo tipológico, que não ultrapassa a descrição e classificação dos fenômenos (Moraes, 2007); a adoção do "paradigma da simplificação", de Edgar Morin, citado por Souza (1997); redução dos aspectos sociais à natureza dos aspectos físicos ao utilizar a abordagem sistêmica sem o devido cuidado (Leff, 2007).

Perante as demais ciências, a geografia tem a vantagem de trabalhar com os objetos e as ações concomitantemente (Santos, 2000). Além disso, a quantidade de aspectos distintos que podem ser incluídos na análise, idealmente aspectos físicos e sociais, dificilmente pode ser abarcada por outros campos do conhecimento. A noção de complexidade e a capacidade de operacionalização adequada do conceito são do mesmo modo um ponto positivo na prática geográfica (Santos, 2000; Carvalho, 1999). Dadas essas vantagens, as contribuições futuras por parte dos geógrafos para o tratamento da crise ambiental são promissoras e espera-se que suas vozes sejam ouvidas não apenas pelos tomadores de decisão, mas também pelos pesquisadores de outros ramos do conhecimento, culminando em uma mudança de mentalidade, que levaria a uma mudança nos processos produtivos e finalmente, na qualidade de vida. 


\section{Referências}

AJARA, C. A abordagem geográfica: suas possibilidades no tratamento da questão ambiental. In: MESQUITA, O. V.; SILVA, S. T. (Coord.) Geografia e questão ambiental. Rio de Janeiro: FIBGE, 1993. p.9-11.

ALIER, J. M. O ecologismo dos pobres: conflitos ambientais e linguagens de valorização. São Paulo: Contexto, 2007.

CARVALHO, M. B. de. Geografia e complexidade. Revista Electrónica de Geografia y Ciencias Sociales, Barcelona, n.34, fev.1999. Disponível em: <http://www.ub.edu/ geocrit/sn-34.htm>. Acesso em: 20 out. 2013.

CHRISTOFOLETTI, A. A geografia física no estudo das mudanças ambientais. In: CHRISTOFOLETTI, A. et al. (Org.) Geografia e meio ambiente no Brasil. São Paulo: Hucitec, 1995. p.334-45.

CORRÊA, R. L. Interações espaciais. In: CASTRO, I. E. de et al. (Org.) Explorações geográficas: percursos no fim do século. Rio de Janeiro: Bertrand Brasil, 1997. p.279-318.

FARENZENA, D.; TONINI, I. M.; CASSOL, R. Considerações sobre a temática ambiental em Geografia. Geografia: Ensino \& Pesquisa, Santa Maria, v.11, n.1, p.1-8, 2001.

GEORGE, P. A ação do homem. São Paulo: Difusão Europeia do Livro, 1970.

. O meio ambiente. São Paulo: Difusão Europeia do Livro, 1973.

GOMES, P. C. C. Geografia e modernidade. 10.ed. Rio de Janeiro: Bertrand Brasil, 2011.

LEFF, E. Epistemologia ambiental. 4.ed. São Paulo: Cortez, 2007.

MEGALE, J. F. Geografia e sociologia em Max Sorre. São Paulo: Instituto de Pesquisas Econômicas, 1983.

MENDONÇA, F. Geografia e meio ambiente. 9.ed. São Paulo: Contexto, 2012.

MORAES, A. C. R. Geografia: pequena história crítica. 21.ed. São Paulo: Hucitec, 2007.

MOREIRA, R. Para onde vai o pensamento geográfico? Por uma epistemologia crítica. São Paulo: Contexto, 2006.

PÁDUA, J. A. As bases teóricas da história ambiental. Estudos Avançados, São Paulo, v.24, n.68, p.81-101, 2010.

PORTO-GONÇALVES, C. W. Possibilidades e limites da ciência e da técnica diante da questão ambiental. Geosul, Florianópolis, v.3, n.5, p.7-40, 1988.

. Formação socioespacial e questão ambiental Brasil. In: CHRITOFOLETTI,

A. et al. (Org.) Geografia e meio ambiente no Brasil. São Paulo: Hucitec, 1995. p.30945 .

RAMÃO, F. de S. A ação do homem e a ciência do meio ambiente humano: a relevância do trabalho de Pierre George. In: III ENCONTRO NACIONAL DE HISTÓRIA DO PENSAMENTO GEOGRÁFICO. I Encontro Nacional de Geografia Histórica, 2012, Rio de Janeiro. Anais eletrônicos... Rio de Janeiro: UFRJ, 2012. Disponível em: <http://www.3hpglgh.net/gt_10/GT\%2010-\%20341\%20-\%20RAMAO_FS.pdf>. Acesso em: 25 out. 2013. 
SANTOS, M. O período técnico-científico e os estudos geográficos. Revista do Departamento de Geografia, São Paulo, v.4, p.15-20, 1985.

$106,1992$.

A redescoberta da natureza. Estudos Avançados, São Paulo, v.6, n.14, p.95-

A natureza do espaço: técnica e tempo, razão e emoção. São Paulo: Hucitec, 1996.

O papel ativo da geografia: um manifesto. Revista Território, Rio de Janeiro, ano V, n.9, p.103-109, jul./dez. 2000.

. A questão do meio ambiente: desafios para a construção de uma perspectiva transdisciplinar. Revista de Gestão Integrada em Saúde do Trabalho e Meio Ambiente, São Paulo, v.1, n.1, ago. 2006. Disponível em: <http://www.interfacehs.sp.senac.br/br/ traducoes.asp? ed=1\&cod_artigo=12>. Acesso em: 10 out. 2013.

SORRE, M. O espaço do geógrafo e do sociólogo. In: MEGALE, J. F. (Org.) Marx Sorre: Geografia. São Paulo: Ática, 1984.

SOUZA, M. L. de S. A expulsão do paraíso. O "paradigma da complexidade” e o desenvolvimento sócio-espacial. In: CASTRO, I. E. de et al. (Org.) Explorações geográficas: percursos no fim do século. Rio de Janeiro: Bertrand Brasil, 1997. p.13-87.

SUERTEGARAY, D. M. A. A Geografia Física no final do século XX. Boletim Gaúcho de Geografia, Porto Alegre, v.18, p.27-31, 1991.

RESUMO - Diante da crise ambiental atual, diversas disciplinas científicas têm se voltado para sua análise, a fim de apontar soluções para dirimir ou minimizar os danos ambientais e sociais causados pelas atividades econômicas e por outros tipos de fatores de pressão ambiental. Este artigo propõe-se inicialmente a mostrar sucintamente como mudou a visão geográfica predominante no mundo ocidental a respeito da relação entre as populações humanas e o ambiente. Uma mudança de visão que foi reflexo das mudanças que estavam em curso na geografia como um todo, resguardadas as diferenças entre os países. Discute-se ainda que a crise ambiental é uma crise do conhecimento, como afirmam cada vez mais autores. Este texto culmina com as virtudes e limitações da geografia na busca desse entendimento, no intuito de colaborar para seu avançar.

PALAVRAS-CHAVE: Epistemologia ambiental, Crise ambiental, Pensamento geográfico.

ABSTRACT - Given the current environmental crisis, various scientific disciplines have striven to analyze it and identify solutions to resolve or minimize the environmental and social damage caused by economic activities and other types of environmental stress factors. This article proposes to briefly show how the predominant geographic vision has changed in the Western world with regard to the relationship between human populations and the environment. This change of vision was a reflection of the changes that were taking place in Geography as a whole, with allowances for differences between countries. It is also argued that the environmental crisis is a crisis of knowledge, as some 
authors claim. The text culminates with the virtues and limitations of Geography in the pursuit of this understanding, with the aim of advancing it.

KEYWORDS: Environmental epistemology, Environmental crisis, Geographical thinking.

Raquel Dezidério Souto é candidata a doutora em Geografia no Programa de Pós-Graduação em Geografia da Universidade Federal do Rio de Janeiro. Oceanógrafa pela Universidade do Estado do Rio de Janeiro. @ - raquel.deziderio@gmail.com

Recebido em $1^{\circ}$.6.2014 e aceito em 3.5.2015.

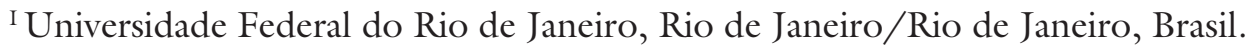

